Portland State University

PDXScholar

Political Science Faculty Publications and

Presentations

Political Science

$11-2002$

\title{
Conflict Emergence and Escalation in Interactive International Dyads
}

David Todd Kinsella

Portland State University

Bruce M. Russett

Yale University

Follow this and additional works at: https://pdxscholar.library.pdx.edu/polisci_fac

Part of the International Relations Commons, and the Models and Methods Commons Let us know how access to this document benefits you.

Citation Details

David Todd Kinsella and Bruce M. Russett. Conflict emergence and escalation in interactive international dyads. Journal of Politics, 64 (4), November 2002, 1045-1068.

This Article is brought to you for free and open access. It has been accepted for inclusion in Political Science Faculty Publications and Presentations by an authorized administrator of PDXScholar. Please contact us if we can make this document more accessible: pdxscholar@pdx.edu. 


\title{
Conflict Emergence and Escalation in Interactive International Dyads
}

\author{
David Kinsella \\ Portland State University \\ Bruce Russett \\ Yale University
}

\begin{abstract}
We examine whether the conditions affecting initial expressions of hostility are similar to those affecting militarized disputes. Analyzing dyadic interactions during the years 1951-1992, we estimate a model to take into account selection effects and check it against another allowing conjunctive causation. Both provide close approximations to theoretical models of the conflict process and yield similar results. We confirm Kant's belief that all states are subject to the realist conditions of interstate competition that makes disputes likely, but that liberal influences, if present, can constrain the escalation of such disputes to war. Several influences on the conflict process have nonmonotonic effects over the range of state behavior. Geopolitical factors affect the opportunity for conflict more at lower levels of the conflict process, when less information is available regarding acceptable settlements and actors' resolve, than at higher levels. Factors affecting willingness gain importance as the conflict process unfolds because they facilitate the flow of information relevant to the ongoing dispute. The proposition that democracy and interdependence encourage diplomatic conflicts as signals of resolve is not supported.
\end{abstract}

\begin{abstract}
A lthough militarized conflict between states is rare, diplomatic and other forms of low-level interstate conflict are not rare, and they have the potential to escalate to more violent forms of dispute. Consequently, scholars and policy makers have a great interest in the tools of conflict management and early warning. It may be that the knowledge we have accumulated about the effects of liberal political and economic processes, as well as geopolitical factors, on war and other forms of militarized dispute also holds at the less violent end of the conflict spectrum. But maybe not. This is important to know, for although efforts to manage and resolve conflict should be undertaken at all stages of the conflict process, it is probably the case that the chances of success are im-

We thank the Ford Foundation and the Weatherhead Initiative on Military Conflict as a Public Health Problem for financial support, and Bear Braumoeller, Paul Huth, John Oneal, Alastair Smith, Allan Stam, Harvey Starr, and James Vreeland for comments and suggestions. An earlier version was presented at the Conference on the Political Economy of International Conflict, Yale University, March 23-24, 2001. Our data are available at 〈http://www.yale.edu/unsy/democ/democ1.htm〉.
\end{abstract}


proved when efforts are initiated earlier rather than later. If so, we should focus on factors that are likely to have maximal impact at that particular phase of an evolving dispute.

Formal theories of interstate conflict—crises, militarized disputes, all-out warconceptualize such events in terms of moves and countermoves and thus attempt to model stages of the conflict process. Bringing our empirical models closer into line with these formal models for purposes of testing hypotheses stands as a significant challenge for future conflict research, in terms of both data collection and analysis. We take one step in this direction by considering the range of conflictual interstate behavior and examine whether in the context of a single empirical model, the conditions affecting initial expressions of hostility are similar to those affecting militarized disputes (MIDs), which are not only more serious but also represent subsequent stages in the conflict process. Most research undertaken to explain the occurrence of international conflict has employed additive models to assess the impact of various factors, and it usually has assumed that the relationships between conflictual behavior and its correlates are monotonic. Often, however, alternative statistical models can provide a closer approximation to theory.

The literature suggests a readily identifiable set of influences on international conflict, influences that might be exercised at multiple points in the conflict process. There is reason to expect a particular pattern in the relative weightiness of these influences, with some factors being more important in earlier stages of an unfolding process and others more important at later stages. We go on to show that our conceptualization of these different types of influences is borne out by the empirical evidence. Our analysis takes up a variety of related issues: the role of low-level conflict and signaling in rational models of bargaining, especially as they relate to the liberal peace hypothesis; problems of selection bias; the theoretical and methodological implications of differentiating politically relevant dyads from others; and contingent causation and the distinction between the opportunity and the willingness to initiate disputes.

\section{Signaling and Selection}

In the past decade, the systematic analysis of international conflict has focused on characteristics of the relations between pairs of nation-states (dyads). The theoretical literature increasingly has incorporated the notion that conflict unfolds in stages. This is a natural outgrowth of using sequential strategic choice models to formalize the logic of crisis interaction and to frame quantitative empirical testing. A key premise is that fully informed states can generally resolve their disputes before resorting to force (Fearon 1995). If a settlement acceptable to both sides is knowable, rational leaders will prefer to reach these settlements through nonviolent forms of interaction rather than pay the costs of war to arrive at the same outcome. War and other costly contests can be explained by states' lack of information. Each side's degree of commitment or 
resolve in achieving an acceptable outcome matters for arriving at a negotiated settlement prior to war, but it is private information. States can convey this information through their actions, but they often have incentives to misrepresent their resolve so as to achieve more favorable settlements.

Information asymmetries can be overcome only if actions intended to convey private information are credible. Costly actions send credible signals because only states that are committed to a particular outcome are willing to communicate their resolve in a way that imposes extra costs on them, either now or in the future. This insight further clarifies some causal mechanisms behind the "democratic peace." Diplomatic protests and sanctions, even those falling short of an explicit or discernible threat to use force, may send signals that a state will at some point be prepared to use military force to protect its interests. Such signals may be more believable when sent by democratic states because elected governments pay steeper domestic "audience costs" when their bluffs are called by foreign opponents (Fearon 1994a, Smith 1998a). But the signals might be less credible if directed against other democracies since the domestic audience may perceive the use of force against another democracy as a sign of an incompetent foreign policy (Mintz and Geva 1993). Democracies thus make fewer idle threats, so the conflictual diplomatic behavior they do engage in contains credible information about their resolve. A domestic political opposition can enhance the credibility of such signals when opposition parties echo the foreign policy commitments of the party in power. Even a silent (but not suppressed) domestic opposition is conducive to effective signaling since democratic governance is transparent and potential foreign opponents assume that any disunity of purpose will be reflected in a democracy's domestic political discourse (Schultz 1998, 1999).

The ability of democratic states to signal resolve should reduce the likelihood that they will become involved in militarized disputes, especially with other democracies. ${ }^{1}$ Their actions tend to reveal private information upon which peaceful bargains can be struck. Yet the implications for their involvement in less severe forms of conflict are less clear. A signaling logic suggests that audience costs should dissuade democratic states from engaging in behavior that misrepresents privately held information and also that the transparency of democratic institutions should allow foreign opponents to perceive their resolve correctly (Bueno de Mesquita and Lalman 1992; Starr 1992), but it says little about how often democracies or other regime types engage in signaling behavior. One reasonable extension of the argument is that because democracies are likely to experience fewer challenges to their signals of resolve, they have less need to reiterate their resolve by sending additional costly signals. Other things

\footnotetext{
${ }^{1}$ Schultz's argument about the transparency of democratic institutions and the increased likelihood of peaceful outcomes is a monadic claim, but he does say that "we can surmise that ... the probability of war [in a democratic dyad] would be lower than in an interaction involving one democracy or none" (Schultz 1998, 840; also see Schultz 2002).
} 
being equal, that implies a lower likelihood of involvement in all forms of conflictual behavior, for which there is some empirical evidence (e.g., Leeds and Davis 1999).

There are other views, however. Democratic states treat the inherent credibility of their signals as an asset to be exploited in their international dealings. If experience has shown their leaders that diplomatic and other nonmilitary challenges bring payoffs without a high risk of escalation to violence, they may actually have more incentive than other regime types to act at the lower end of the conflict spectrum (Morrow 2000). Because democratic dyads often are economically interdependent, their more numerous commercial linkages may also provide more opportunities to signal resolve below the threshold of the threat or use of force. Compared to other dyads, then, democratic and interdependent dyads may well experience more lower level diplomatic and economic disputes (Gartzke and Jo 2001; Gartzke, Li, and Boehmer 2001). ${ }^{2}$ This leads to two empirical questions: what is the net effect of these divergent tendencies, and are they manifest to varying degrees at different points along the conflict continuum (which often correspond to different stages in a sequential conflict process)?

Since many of the insights on signaling come from the literature on crisis interaction (e.g., Bueno de Mesquita, Morrow, and Zorick 1997; Morrow 1989), it may not be surprising that expectations are clearer at the more violent end of the spectrum. Thus, when at least one state in an interacting dyad is democratic, the credibility of signals should help to diffuse the conflict process before it reaches the level of use of force and, very possibly, before the display or even the threat of force. ${ }^{3}$ The latter is the threshold for a MID, so the signaling logic comports well with the robust empirical finding that jointly democratic dyads experience fewer MID initiations and the common if less robust finding that democratic states experience fewer violent disputes with nondemocratic states (Rummel 1995; Russett and Oneal 2001, chap. 3). It is at lower levels of conflict that predictions become competing or murky due to the countervailing tendencies just discussed and the fact that little in the signaling literature provides more specific hypotheses about diplomatic, economic, and other forms of nonmilitarized conflict behavior.

If low-level signalling of resolve or interest affects the likelihood of escalation, one must consider how selection effects potentially undermine inferences about war and peace (Smith 1998b; see also King 1989, chap. 9). If the functioning of democratic institutions increases the probability that democratic dy-

\footnotetext{
${ }^{2}$ Gartzke and Jo (2001) actually distinguish two variants of the signaling argument. "Cheap talk" signaling — which should really be labeled "credible talk" signaling - refers to the ability of democracies to communicate resolve using very low-level (i.e., verbal) conflictual behavior. Therefore, they predict that although democracies will engage more frequently in very low-level conflict, they will become involved in fewer conflicts involving more than verbal exchanges.

${ }^{3}$ Eyerman and Hart (1996), using the SHERFACS scale that begins with a dispute phase preceding the conflict phase (a threat to use force, but not yet actual use), appear to support this.
} 
ads will be selected out of the sample of dyads at risk of military conflict, then those that remain are not representative of the population of democratic dyads, making it difficult to arrive at accurate estimates of the net impact of democracy at that level of conflict. The same may hold for economically interdependent dyads.

The potential for selection bias is not limited to large-N analyses of interstate conflict. Some case-study work focuses on low-level militarized disputes, treating the very emergence of such a dispute between democracies as an exception to the democratic peace and then focusing on whether and why further escalation to all-out war may not occur (e.g., Layne 1995; Rock 1997). But if one regards low-level militarized disputes as possible though rare phenomena between democracies, then two questions are relevant. One is why the militarized disputes that do arise do not escalate to war. The other is why so few of the many diplomatic disputes between democracies ever escalate to any form of militarized dispute in the first place (Russett 1995). Studying "near misses" in detail merely focuses attention on an unrepresentative sample of democratic dyads - outliers where factors outside the theory exert weightier impact. Although some argue that such studies are useful for theory building, if the intention is to elucidate causal mechanisms consistent with the theory under examination, they are more likely to muddle than to sharpen our understanding (Morrow 2000). By shifting attention to lower levels of conflict, we can begin to take into account the "dogs that didn't bark," at least some of them.

\section{Opportunity, Willingness, and Information}

Although it seems logically sound, we are unpersuaded by the claim that democracies might more often engage in nonmilitarized conflictual behavior because the risk of escalation to violence is lower than for nondemocracies. Like many other efforts to provide the microfoundations of patterned state behavior, this is often a monadic line of argument, but it stands to reason that true, democratic dyads should experience quite a bit more low-level conflict since a similar calculus is operating simultaneously on both states. Yet liberal theory, while certainly not positing complete harmony of interests between democratic states, does suggest that the operation of liberal norms and institutions should make unnecessary this kind of posturing as a means to convey private information. Costly signals are not needed when two states are linked by shared norms and practices of conflict resolution: there are many ways to convey private information short of threatening to use force.

Nonetheless, we do need to take seriously the possibility that the effects of democracy and interdependence, as well as other factors, are not monotonic along the range of international conflict. What patterns do we expect? By definition, at early stages of the conflict process states have engaged in minimal interaction over a particular issue in dispute (Bremer 1993). Since state behavior conveys information (whether accurate or not), there is less of it available 
as the process is beginning to unfold, so states must rely more on contextual factors like geographic proximity and state capabilities when making decisions. Continuing interaction over a contentious issue is like an evolving bargaining process in which more information becomes available to the participants. As more information is exchanged through signaling, the impact of contextual factors on state behavior is likely to recede. Then, influences identified with liberal theory - democratic governance, economic interdependence, and membership in international organizations, all of which are indicative of dyadic interactions that communicate private information - should become relatively more important than they were at earlier stages.

The possibility of interaction varies greatly across dyads. Relations within many dyads are extremely "thin," with little trade, interactions in only a few international organizations, and little ability or incentive to engage in violent conflict. Such dyads, rather than simply labeled peaceful, are better characterized as pairs of states that are nearly irrelevant to each other. "Peace" between them thus is more nearly explained by their lack of interaction than by the kinds of positive interactions deriving from trade, similar political systems, alliances, or other influences commonly identified as contributors to peace. Consequently, many analysts (Bremer 1992a, 1992b, 1993; Maoz 1998; Maoz and Russett 1993; Russett and Oneal 2001) focus on politically relevant dyads (PRDs), defined as pairs of states that are contiguous by land or narrow bodies of water or contain a major power with geographically expansive interests and able to exert power over a large segment of the globe. This theoretically derived limitation incorporates the widely confirmed finding that geographical proximity and contiguity together form the single best predictor of international violence and that great powers engage in far more violent conflict than do weaker states. It thus concentrates attention on the $20 \%$ or so of all dyads that account for nearly $90 \%$ of all MIDs and avoids trying to explain the absence of conflict between all the pairs of states that have neither the capability nor incentive to fight each other. ${ }^{4}$

Analyses limited to the politically relevant dyads often reach similar conclusions as those addressed to all dyads in the international system, and, not surprisingly, the relationships are typically much stronger in the former set (Lemke and Reed 2001a). But they are not always the same. For example, some analyses have found common membership in international organizations to have a modest but significant effect in reducing conflict among the PRDs, but not among all dyads (Oneal and Russett 1999a). High levels of dyadic trade show a strong and significant conflict-reducing effect among PRDs, even in all-dyad analyses (Bennett and Stam 2000; Oneal and Russett 1999b), but among nonPRDs alone trade may be positively related to conflict if there is no adequate

\footnotetext{
${ }^{4}$ In the context of the early 1990 s, when dyadic analysis came to the fore, limiting the analysis also reduced computational demands on the technology then available. This benefit, however, quickly became irrelevant as the hardware and software developed.
} 
control for distance. The latter of course does not mean that the absence of trade causes peace. It means that the cost and time of shipping goods great distances discourage trade just as they decrease the incentive and capability to ship fighting forces. Trade and conflict are correlated because both drop with distance, not because trade causes conflict.

Consequently, variables affecting the frequency of conflict may not produce coefficient estimates of similar size for PRDs as for "nonrelevant" dyads, or even estimates with the same sign. Despite the advantages of concentrating most analysis on the PRDs, something is lost by doing so. After all, there are some militarized disputes between non-PRDs, and we need to explain them, too. For example, Iraq and Israel have fought though neither is a major power and they do not share a border. Early work by geographers O'Loughlin (1986) and Anselin (1988) noted the "regional" effects of second- and third-order proximity, and theoretically informed efforts by Lemke (1995) and Maoz (1996) help to expand the definition of politically relevant dyads, but some MIDs and even a few wars involving non-PRDs remain beyond their scope.

How might we reconceptualize political relevance and the risk of conflict without relying on assumptions about proximity or global reach, however well informed? One productive approach is in the concepts of opportunity and willingness to come into conflict (Most and Starr 1989). Siverson and Starr (1991, 24) develop the term opportunity "to mean the possibilities that are available to any entity within the environment." Here they put equal power ratio along with proximity, contiguity, and major power status. Their concept of willingness would include the Kantian suppressors of conflict: democracy, interdependence, open economies, and international organizations. It also includes the decision to conclude an alliance, which "reflects a willingness to accept the potential costs of alliance as balanced against potential gains." Like form of government, low trade barriers, and decisions to join intergovernmental organizations (IGOs), alliances result from "conscious choices of decision makers that indicate positions of policy preference" (Siverson and Starr 1991, 26). Similarly, in Bueno de Mesquita's (1981) expected-utility model, power discounted by distance indicates the expectation of victory and, hence, opportunity, and alliances - and, by reasonable extension from his specification, political system, trade, and IGO memberships - indicate the utility of winning and thus the willingness to fight. ${ }^{5}$

The categories of opportunity and willingness also imply something about the relative importance of various influences on the conflict process, in terms of their potential to convey information that exists or is most relevant at particular stages of the process. Many of the factors we associate with opportunity in the analysis of interstate conflict, especially the geopolitical variables highlighted in realist theory, are either unchanging or change rather slowly. Consequently, as indicators of interests and capabilities, they represent information

\footnotetext{
${ }^{5}$ Bueno de Mesquita also includes a state's allies, and the probability they will assist it, in his power calculations. We briefly discuss the matter of joiners below.
} 
that tends to be better known to interacting states - information that is not only available, but also reasonably unbiased - and thus more likely to be drawn upon at earlier stages of a conflictual interaction when other information (like commitment and resolve) is not well known.

The factors we associate with willingness are, by definition, closer to actual interactions in a given instance. Liberal theory highlights the conflict-suppressing effects of democracy, trade, and other forms of societal openness and integration, which provide not only a basis for shared interests and norms, but also a multiplicity of channels for the flow of information. As an interstate conflict unfolds and evolves, these channels facilitate the flow of information relevant to a settlement of the conflict. Whether the signals convey a willingness to fight or to back down, the importance of societal linkages (or their absence) increases relative to geopolitical influences, which are still relevant but are now accompanied by information specific to the ongoing interaction. The Kantian variables do not measure the content of signals sent and received, but they do indicate the existence of channels through which this information flows.

The concepts of opportunity and willingness contribute to a theoretically more integrated explanation of militarized disputes. A related view appears in a book on how scientists explain disease. Thagard (1999) distinguishes between environmental inducements of genetic mutation on the one hand and bodily suppressors of harmful mutations on the other. The combination of these two influences accounts for the progression from simple exposure to the development of many diseases in acute form. This insight can be applied to international relations if we divide the list of influences on the occurrence of military conflict into two such groups (Russett 2003).

Inducements to conflict include proximity, contiguity, and major power status. To these can be added a near-equal power ratio. At least one of them is a near-necessary condition for a "mutation" or event: a serious diplomatic dispute. Without them, most states have little opportunity or willingness to come into conflict; but with them, there is a potential for political and diplomatic conflicts of interest that may under certain conditions escalate into a MID.

Other variables are more usefully considered as potential suppressors. The weakness of one or more of them allows the process of diplomatic dispute "mutation" to advance and become a MID. They include joint democracy, high mutual trade relative to GDP, economies generally open to trade with many nations, and shared IGO memberships, which include but are not limited to military alliances. ${ }^{6}$ Thus "peaceful" dyads may avoid MIDs for different rea-

\footnotetext{
${ }^{6}$ Possibly a very unequal power ratio between the two states could be considered a suppressor of violent conflict, on the grounds that the weaker state will be deterred from any act that might provoke the stronger one to violent action. This reasoning can be pushed back to the inducement stage, in that relatively equal power relations in a realist world of balanced power induces states to raise diplomatic issues precisely because of the uncertainty about the outcome. (See Wagner 2000 for a rationalist explanation of why war is more probable in closely balanced dyads than in unbal-
} 
sons: because they are distant and lack other inducements to conflict, or because they experience enough suppressors to prevent any conflicts from escalating to violence (Bremer 1992a). MID-prone dyads, by contrast, are similar in sharing both many inducements and few suppressors.

This analogy fits well with the opportunity and willingness perspective on situational, context-oriented laws that work best for a specific subset of cases (Cioffi-Revilla and Starr 1995; Goertz 1994). ${ }^{7}$ In effect, inducements set the context - the subset of cases where there is an opportunity to fight - and the absence of suppressors offers a powerful explanation for the emergence of violent conflicts within this subset.

\section{Data Analysis}

This discussion suggests two related improvements to the standard approach to modeling international conflict: we should consider a wider range of the conflict spectrum, and in doing so we should take into account the availability of information at different stages in the conflict process. One way to do this is to specify models that incorporate selection effects. ${ }^{8}$

Consider an underlying relationship between serious, potentially violent dyadic conflict, $y^{*}$, and a vector of variables associated with opportunity, $X_{1 k}$, and another vector associated with willingness, $X_{2 l}$,

$$
y^{*}=X_{1 k} \beta_{1}+X_{2 l} \beta_{2}+u_{1} \text {. }
$$

anced ones, contra Waltz 1979.) Moreover, the power ratio shares with the other inducements the characteristic of being relatively stable and fixed, only slowly if at all subject to change by deliberate policy choice. The suppressor variables, by contrast, all are more clearly subject to political decision and change. For a historian's use of the disease inducement and suppressor analogy, see Schroeder $(2000,208)$.

${ }^{7}$ Goertz (1994) usefully distinguishes between context as "cause" and context as "barrier." Thus, the presence of what we refer to as inducements to conflict are causes in this sense, while their absence can be seen as barriers to conflict. Compared to these contextual factors, what we refer to as suppressors of conflict are more "active" in dampening the likelihood of conflict.

${ }^{8}$ Reed (2000) addresses the issue of selection bias in distinguishing between the causes of militarized dispute initiation and the causes of dispute escalation, possibly including full-scale war. He confirms Kugler and Lemke's (1996) finding that whereas relative power parity between two states contributes to the onset of militarized disputes, once the states are involved in a dispute, the effect of power parity switches, with the uncertainty about the outcome of a war diminishing incentives to escalate. Similarly, Reed finds that though joint democracy may help prevent the onset of a militarized dispute, it has no significant effect on whether a dispute will escalate simply because most democratic dyads have been selected out of the sample of MID participants. We have some reservations about the five-point MID classification as a true scale of escalation. For instance, about $70 \%$ of all events short of war fall into the single category of "use of force," with few events classified at the lower levels of "threat of force" and "demonstration of force." Nevertheless, Reed is on to a good idea, which we want to pursue further by considering earlier stages of the conflict process (see also Huth 1996, 2002). 
We observe the onset of a militarized dispute, $y^{m}$, as a binary outcome,

$$
y^{m}=\left(y^{*}>0\right),
$$

but this outcome is possible only if some conflict of interest between the two states comes out into the open as a diplomatic dispute, $y^{s}$, which is also a function of opportunity and willingness. That is, underlying dyadic hostility can only "mutate" into a MID if

$$
y^{s}=\left(X_{1 k} \gamma_{1}+X_{2 l} \gamma_{2}+u_{2}>0\right) .
$$

We expect the estimated coefficients in $\beta_{1}$ to have positive signs since the variables we identify as falling into the category of opportunity represent inducements to conflict. The estimates in $\beta_{2}$ should have negative signs because the willingness variables are conflict suppressors. We might hypothesize the same for $\gamma_{1}$ and $\gamma_{2}$, respectively. However, if the selection effect is such that certain types of states "substitute" diplomatic or economic hostility for militarized hostility because low-level conflict is seen as an effective way to signal resolve, then presumed suppressors like joint democracy and economic interdependence may actually yield coefficients with positive signs. For the reasons discussed above, we find this alternative hypothesis less persuasive, but the logic is compelling enough that the proposition should be taken seriously.

The potential for selection bias comes from a correlation between the error terms $u_{1}$ and $u_{2}$. If an unobserved variable like commitment or resolve affects the likelihood that a dyad will experience some level of conflict, and also the likelihood that the disputants will be impelled to find a settlement prior to the militarization of the dispute, then that correlation, $\rho$, will be negative. The literature on costly signals highlights this selection effect and warns of the possibility of erroneous inferences. Fortunately, off-the-shelf procedures are available for overcoming these problems (Dubin and Rivers 1990). One solution, drawing on Heckman (1979), is to model the selection process using probit (or logit) and then compute the hazard rate for nonselection. With this hazard rate included as a regressor in a separate probit (or logit) model of the outcome, one can derive consistent estimates. As an alternative to this two-stage estimator, it is increasingly common to model the selection process and the outcome jointly using maximum likelihood estimation (with the two-stage estimates serving as starting values). Both approaches are represented in international relations work (e.g., Blanton 2000; Huth 1996; Meernik 2000; Reed 2000). We generate the results below using maximum likelihood.

Events data provide a useful indication of the emergence of low-level conflict within a dyad. To model this selection process, we consult three events databases: the Conflict and Peace Data Bank (COPDAB) (Azar 1993); the World Event/Interaction Survey (WEIS) (Tomlinson 1993); and the Protocol for the Assessment of Nonviolent Direct Action (PANDA) (Bond and Bond 1998). Each reports conflictual behavior undertaken by all states in the international sys- 
tem, ranging from mild verbal expressions of discord to full-scale war. Their temporal coverage differs but they overlap, so among them we can construct a binary variable, measured annually from 1950 to 1992, indicating the onset of any dyadic dispute clearing a minimum threshold of conflict, which we operationalize as strong verbal hostility. ${ }^{9}$ The experience of such hostile behavior may prove a more conceptually satisfying way to identify politically relevant dyads than do the situational criteria of proximity and presence of a major power.

\section{Findings}

Our analysis brings together several important extensions discussed above to the program of research on "the Kantian Peace" (e.g., Russett and Oneal 2001). It advances empirical analysis to incorporate insights from formal models of interstate conflict. The role of information and signaling has been the focus of much choice-theoretic work in recent years, and the implications for selection effects, and thus the robustness of previous empirical findings, are beginning to be realized. We deal with these issues by examining a wider range of conflictual behavior so as to model explicitly the selection effects that may have misled earlier empirical analyses of militarized disputes only. This allows us to test our hypothesis about the effects of opportunity and willingness being nonmonotonic over different stages of the conflict process.

Before turning to a probit analysis with selection, we present results from the more common standard probit regression used to model the onset of a militarized dispute. The data consist of a pooled time-series of all dyads during the years 1951 to 1992 . We use both the variables identified above as defined and measured in Oneal and Russett (1999b) and the data from that project. ${ }^{10}$ The

\footnotetext{
${ }^{9}$ This variable is coded 1 for any dyad-year in which at least one of the databases reports a qualifying event. COPDAB conflict categories are arranged on an ordinal scale. Our minimum threshold is the category "strong verbal expressions displaying hostility" (e.g., condemnation of actions or policies, denunciation of leaders, system, or ideology, cancellation of state visits or summits), which is considered more conflictual than "mild verbal expressions displaying discord" (e.g., low-key objections to policy or behavior, expressed discontent through a third party) and less conflictual than "diplomatic-economic hostile actions" (e.g., recall or expulsion of ambassadors, economic sanctions, troop mobilizations). WEIS and PANDA categories are nominal, but Goldstein (1992) developed an interval-scaling system that is now widely used. We count any conflictual event rising to at least the severity level of 2.2 on that scale, which includes the categories "charge, criticize, blame" and "cancel or postpone planned events." These types of interaction are considered more conflictual than, for example, the category "informal complaint" and less conflictual than "formal complaint or protest." A wide-ranging examination of the uses and limitations of events data is by Schrodt and Gerner (2000).

${ }^{10} \mathrm{All}$ independent variables are lagged one year behind the dependent variable. The analysis incorporates statistical corrections now common in pooled time-series analysis: robust standard errors adjusted for clustering on dyads, and the Beck, Katz, and Tucker (1998) spline correction for time-dependence among observations. The spline correction is most commonly used in this literature to control for time dependence, with the General Estimating Equation (GEE) being another
} 
opportunity variables are: proximity defined as the (logged) distance in miles between states, subtracted from zero; a dummy variable coded 1 if they or their colonies are contiguous by land or within 150 miles by water; a dummy variable indicating whether the dyad includes a major power; and the ratio of the power of the stronger state to that of the weaker, subtracted from zero. The willingness variables are: joint democracy measured as the level of democracy reached by the less democratic state in the dyad; the dyadic trade dependence of the state with the lower ratio of dyadic trade to GDP; the economic openness of the state with the lower ratio of total trade to GDP; the number of IGOs in which the two states share membership; and a dummy variable for whether the states are allied.

The first two columns of Table 1 show the standard probit estimates for MID onset, the most common dependent variable in this literature. ${ }^{11}$ The model includes all the variables associated with opportunity (inducements) and willingness (suppressors). The first entry for each variable is the estimated coefficient from the probit regression, and next to that is its standard error. Note first that the impact of every variable except economic openness is statistically significant using a one-tailed test. The results correspond closely with other findings reported in the literature. Democracy, interdependence, and alliances are strongly associated with a decline in the probability of a militarized dispute; equal power, contiguity, proximity, and a major power in the dyad all are associated with greater probability of a MID. An economy open to trade has the expected negative sign but is not statistically significant $(p=0.25)$.

The only counterintuitive result is that sharing more IGO memberships is associated strongly and positively with dispute initiation, rather than negatively as hypothesized. This suggests that joint membership in IGOs does not suppress militarized disputes, but rather encourages or at least is associated with them. In part, it results from the methodological choice to use the Beck, Katz, and Tucker (1998) spline correction for time dependence rather than the General Estimating Equation (GEE). Oneal and Russett (1999a) found their expected dispute-reducing effect emerged only with GEE, for reasons not yet fully clear. ${ }^{12}$ Another possible explanation may lie in limitations of the data. Russett

option. Since both require assumptions that may not be appropriate, neither is fully satisfactory, and consensus on the best method is lacking (see Alt, King, and Signorino 2001). Likelihood ratio tests indicate that the spline variables (a count of the years since the last conflict, plus three natural cubic splines) do capture duration dependence. To reduce clutter, we do not show the spline estimates in the tables.

${ }^{11}$ The MID data are the most recent dyadic compilation and refinement by Zeev Maoz (version 1.1), available at $\langle\mathrm{ftp}: / /$ spirit.tau.ac.il/zeevmaoz/dyadmid60.xls $\rangle$.

${ }^{12}$ When we estimate the MID model using GEE - specifying a binomial distribution for MIDs, a logit link function, and a first-order autoregressive process within dyads - the estimate for IGOs is negative but not statistically significant. This holds whether we estimate the model from the entire data set or the subset of dyad years experiencing at least strong verbal hostility. 
TABLE 1

Probit Estimates for Conflict Opportunity and Willingness, 1951-1992

\begin{tabular}{|c|c|c|c|c|c|c|}
\hline & \multirow{2}{*}{\multicolumn{2}{|c|}{$\frac{\text { Probit }}{\text { Militarized Disputes }}$}} & \multicolumn{4}{|c|}{ Probit with Selection } \\
\hline & & & \multicolumn{2}{|c|}{ Any Conflict } & \multicolumn{2}{|c|}{ Militarized Disputes } \\
\hline & estimate & std. error & estimate & std. error & estimate & std. error \\
\hline \multicolumn{7}{|l|}{ Willingness } \\
\hline Lower Democracy & -0.023 & $0.005^{* *}$ & -0.006 & $0.002 * *$ & -0.014 & $0.004 * *$ \\
\hline Lower Dependence & -36.667 & $10.956^{* *}$ & -9.998 & $2.892 * *$ & -22.045 & $8.288^{* *}$ \\
\hline Lower Economic Openness & -0.185 & 0.161 & -0.087 & $0.046^{* *}$ & -0.238 & $0.184 *$ \\
\hline International Organizations & 0.010 & $0.003^{* *}$ & 0.010 & $0.001^{* *}$ & 0.003 & 0.002 \\
\hline Alliance & -0.207 & $0.079^{* *}$ & 0.055 & $0.026 * *$ & -0.163 & $0.063 * *$ \\
\hline \multicolumn{7}{|l|}{ Opportunity } \\
\hline Equal Power Ratio & 0.048 & $0.019^{* *}$ & 0.055 & $0.006^{* *}$ & 0.008 & 0.022 \\
\hline Contiguity & 1.086 & $0.087^{* *}$ & 0.399 & $0.044 * *$ & 0.762 & $0.094 * *$ \\
\hline Proximity & 0.199 & $0.035^{* *}$ & 0.144 & $0.016^{* *}$ & 0.077 & $0.037^{* *}$ \\
\hline Major Power & 0.849 & $0.079^{* *}$ & 0.955 & $0.030 * *$ & 0.018 & 0.106 \\
\hline Constant & -0.896 & $0.308^{* *}$ & 0.057 & 0.140 & -0.267 & 0.312 \\
\hline Wald $\chi^{2}$ & \multicolumn{2}{|c|}{$1291 * *$} & & & \multicolumn{2}{|c|}{$568 * *$} \\
\hline $\mathrm{N}$ & \multicolumn{2}{|c|}{209,402} & \multicolumn{2}{|c|}{209,402} & \multicolumn{2}{|c|}{11,925} \\
\hline
\end{tabular}

Note: Estimated $\rho=-0.176$; Wald $\chi^{2}=5.88(p=0.015)$ for $\rho=0$. To correct for duration dependence, models include a variable representing the number of years since the last conflict event plus three natural cubic spline variables. For the probit with selection, this correction is incorporated into both the selection and outcome equations. Standard errors are Huber/White ("robust") estimates and also allow for within-dyad dependence.

**significant at the 0.05 level (one-tailed)

*significant at the 0.10 level (one-tailed)

and Oneal (2001, chap. 5) discuss the measurement problems resulting from their simple count of all IGOs without weighting them for importance, function, institutionalization, or power. Boehmer, Gartzke, and Nordstrom (2001) identify similar problems and begin to solve them with a theory about institutionalization and the mediating potential of different types of IGOs. When they recode IGOs using their new criteria, they find that institutionalized IGOs do, as expected, reduce the frequency of MIDs. Further consideration requires a clarification of theory, to which we give some attention below.

Of the 209,402 dyad years for which we have complete data, 11,925 constitute the selected sample of minimally conflictual dyad years, and out of these conflictual dyad years, 745 militarized disputes emerged. Although several discrete conflict events - diplomatic, economic, or military - often comprise a single dispute, the events databases do not link them together as such, and we do not try to distinguish between dispute initiation and continuation when model- 
ing the selection process. Prolonged conflict represents a continuing context for the onset of new militarized disputes and the selection process should be modeled accordingly. In contrast, our interest in MIDs concerns only their initiation, not their prolongation, although others like Reed (2000) have examined selection effects at this higher end of the conflict spectrum.

We should also emphasize that when a dyad year is coded 1 for selection into lower level conflict, it does not necessarily mean that an events database records strong verbal hostility, but that it records at least strong verbal hostility. Nevertheless, interstate conflict almost always unfolds in stages; the vast majority of MIDs are in fact preceded or accompanied by manifestations of diplomatic conflict. For those MIDs that do not evidence lower level diplomatic disputes in the same year, the problem is largely one of incomplete coverage by the media, which are more likely to report on the bigger and more conflictual-and thus newsworthy-events constituting what is often an evolving interstate dispute. Such bias is reflected in events databases because they rely on media reporting as their source of information. ${ }^{13}$

The remaining columns of Table 1 show estimates from the probit model with selection. Columns 3 and 4 are estimates of the impact of the opportunity and willingness variables on the emergence of any conflict within a dyad, including diplomatic disputes. All the estimates are statistically significant, which is not surprising given the very large number of observations. The coefficients for opportunity (proximity, contiguity, equality of power, and major power status) all have the expected signs for conflict inducements. Three of the five factors we hypothesize to suppress the willingness to engage in militarized conflict (joint democracy, interdependence, and economic openness) have that effect on hostile behavior in general. But two unexpected results emerge for the other suppressors: IGOs and alliance have the wrong sign for the hypothesis. While some contributions to the signaling literature would have prepared us for finding positive coefficient estimates for democracy or interdependence, there is little in their arguments to suggest that the logic might apply instead to these other presumed suppressors.

A possible explanation for both unexpected results is suggested by Siverson and Starr (1991, 93), who, despite placing alliances among the (un)willingness variables, note that along with borders, "alliances create the salience and/or the ease of interaction (as predicted by the interaction opportunity model) that significantly increases the probability that states will join ongoing wars." Their attention is to the likelihood of joining an ongoing war on the side of one's ally,

\footnotetext{
${ }^{13}$ Of the 745 dyad years with MIDs, 120 had no conflictual event whatever recorded in any of the three events databases. Events data sets, relying on reports in major news media, tend to underreport events occurring outside arenas of prominent conflict (e.g., superpower interactions during the Cold War, the Middle East). Since the undercounting of lower level conflict is almost certainly the culprit here, as opposed to the overcounting of MIDs, we treat the 120 "missing" conflictual events as measurement errors and recode these dyad years to 1 .
} 
and in itself does not help. ${ }^{14}$ But the statement that formal alliances make alliance partners more salient for each other is helpful. Alliances produce not just bonds of security, but grounds for diplomatic disagreement about institutions, decision-making procedures, burden-sharing, strategy, and related matters. In this light, it is less surprising that alliances emerge in the selection process as inducers of lower level conflict. Similarly, many international organizations (and our IGO measure includes alliances) may increase the salience of their members for each other and raise the possibility of diplomatic and political disputes that will catch the headlines. Moreover, many IGOs are regional and reflect the salience that neighbors already have for each other and often are created to deal with existing disputes. Since IGOs share some variance with the geographical measures (proximity and contiguity), they may not necessarily induce disputes, but they may still be correlated noncausally with them. ${ }^{15}$ Thus Boehmer, Gartzke, and Nordstrom (2001) find that while well institutionalized IGOs are effective in reducing MIDs, measures of preexisting contention among IGO members are associated with a higher incidence of MIDs.

This part of the analysis also raises doubt about some strategic-choice signaling explanations of conflict. One hypothesis, discussed above, holds that democratic institutions or economic interdependence provide means for states to convey their resolve by their actions in diplomatic disputes and that these signals of resolve therefore make it less necessary to escalate the merely diplomatic disputes to militarized ones. This implies that whereas democracy and interdependence will have a negative impact on the probability of MIDs, they not only will have less impact on lower level diplomatic or economic disputes but may even contribute to the frequency of such disputes. But our results do not confirm the latter expectation. Democracy and interdependence do not encourage lower level conflict as an instrument of signaling but, rather, help prevent those disputes as well. Something other than signaling in this sense may be operating, as suggested by theories emphasizing the wider communication of information conducive to bargaining, other aspects of democratic and economic institutions that promote compromise, or the strengthening of common identities (Russett and Oneal 2001, chap. 2).

Now turn to the last two columns of Table 1, which focus on the sample of conflictual dyad years and the onset of militarized disputes. The effect of the power ratio is not significant at all here, confirming Reed's (2000) argument

\footnotetext{
${ }^{14}$ Of the 23 post-World War II warring dyads that were not politically relevant by Lemke and Reed's (2001a) criteria, all but one involve states that joined an ongoing war they did not originate. Of the 22 "irrelevant" joiners, 19 are from widely expanded multi-actor wars: the Korean War, the Vietnam War, and the Gulf War against Iraq. Overwhelmingly, then, joiners are small states operating under the umbrella of major powers who bring them in and frequently provide much of the logistics, equipment, and command and control to make the war-fighting coalition succeed. We tried omitting joiners, but the results were essentially unchanged.

${ }^{15}$ In our data the correlation between shared IGO membership and proximity together with the binary indicator of contiguity is 0.42 .
} 
about the nonmonotonic effects of power parity at different levels of conflict, but calling into question his particular finding that parity is associated with MID onset. Whereas a more equal power ratio provides an opportunity for lower level conflict, it would be wrong to conclude that making the ratio more unequal will help in suppressing the escalation to a militarized dispute. ${ }^{16}$ Major power status also exerts no significant impact on MID onset once we account for selection. Most of the other variables (democracy, dependence, alliance, proximity, and contiguity) have significant effects of the type we predict. The impact of being allied, while associated with salience and the potential for lesser forms of conflict, clearly suppresses the emergence of militarized disputes. The effect of an open economy is also in the direction predicted but is only weakly significant $(p=0.10)$. The unanticipated positive effect of IGOs in the selection process no longer holds when it comes to MID onset; the coefficient is still positive, but its standard error is large and does not support an inference one way or the other.

This analysis does reveal a selection effect, as indicated by the estimate of $\rho$, but it is modest $(-0.18)$ though statistically significant $\left(\chi^{2}=5.9, p=\right.$ 0.015 ). Factors not explicitly included in our model have one effect on dyadic involvement in lower level conflict but a somewhat opposite effect on the onset of militarized disputes. Commitment or resolve is an example of such a factor, difficult to measure and therefore consigned to the error term. As Fearon (1994b) and others have pointed out, states may be more likely to become involved in disputes when they are resolved to secure their interests by force if necessary and confident about ultimately prevailing. Knowing this, their opponents are more inclined to back down before the dispute escalates to violence. We believe that democratic institutions and practices of governance facilitate the sending of credible signals, but the modest selection effect revealed here does not constitute evidence that they are more likely to become involved in lower level conflict for this reason. Joint democracy and interdependence are explicitly represented in the model and evidence suppressing effects on militarized and nonmilitarized disputes. Some states may substitute diplomatic or economic conflict for militarized conflict, but neither democratic nor interdependent states show a particular tendency to do it when interacting with each other.

To compare the effects of opportunity and willingness and to compare their impact at different stages of the conflict process, we should focus not on the coefficients or significance levels, but on the percentage change in the probability of conflict. Table 2 shows these estimates. We compute the baseline probability of conflictual behavior, and the probability of MID onset conditional on such behavior, for contiguous dyads in which the opportunity and willingness

\footnotetext{
${ }^{16}$ Lemke and Reed (2001b) report that while power parity increases the probability that great powers will become rivals, it reduces the likelihood of war once they have become rivals.
} 
TABLE 2

\section{Estimated Change in Risk Probabilities for Conflict Opportunity and Willingness, 1951-1992}

\begin{tabular}{lcc}
\hline & $\% \Delta \operatorname{Pr}($ conflict $=1)$ & $\% \Delta \operatorname{Pr}(\mathrm{MID}=1 \mid$ conflict $=1)$ \\
\hline Willingness & -12.5 & \\
$\quad$ Lower Democracy & -1.5 & -31.7 \\
Lower Dependence & -4.0 & -3.8 \\
Lower Economic Openness & +27.5 & -12.1 \\
International Organizations & +10.1 & {$[+12.1]$} \\
Alliance & & -26.1 \\
Opportunity & +17.2 & {$[+5.3]$} \\
Equal Power Ratio & +30.9 & +22.1 \\
Proximity & +271.7 & {$[+31.5]$} \\
$\quad$ Major Power & 0.100 & 0.079 \\
Baseline & & \\
\hline
\end{tabular}

Note: Baseline probability levels are computed for contiguous, nonallied, nonmajor-power dyads, with lower democracy and lower dependence set at their sample medians and all other variables set at their means. Figures are for a change in a single independent variable from its mean/ median level to the 90th percentile. Brackets indicate that the coefficient estimate for that variable was not statistically significant (see Table 1).

variables are at their mean or median levels. ${ }^{17}$ The change in probability reported for each variable is the percentage difference between this baseline and the probability of conflict when that variable alone is increased to the value corresponding to the 90th percentile in our data. Thus, for the dichotomous measures of alliance and major power, the computed effect is for a dyad that is allied and a dyad in which one or both states is a major power.

The results are very informative. Joint democracy, interdependence, and economic openness each are more important in reducing the risk of militarized disputes than they are in reducing the risk of conflict generally (though they do that, too). When it comes to serious conflict, the magnitude of the risk reduction coming from being allied is greater than the increased risk of low-level conflict due to salience. While these conflict suppressors become more important in reducing the willingness of states to risk more violent conflict, the re-

\footnotetext{
${ }^{17}$ The median is used for dependence, which is highly skewed. Dyads are taken to be nonallied and not including a major power. We compute baseline probabilities for contiguous dyads, even though most are not contiguous, because the likelihood that noncontiguous dyad-years will experience a MID onset is so very low: $0.1 \%$ in our sample. Even for noncontiguous dyads experiencing conflict in a given year, only $2.5 \%$ experience a MID. Therefore, the impact of inducements and suppressors on militarized disputes is more relevant for contiguous dyads, though the model is estimated from data for both types. The percentage of contiguous dyad years in our sample with a MID onset is 7.0; for dyad-years in conflict, 23.0.
} 
verse holds for inducements. This is not surprising in the case of dyads that are geographically proximate and dyads involving at least one major power since they are strongly associated with increased interaction-opportunityand therefore experience a greater likelihood that disagreements, large and small, will arise over a host of issues. Once we account for dyadic interaction turning conflictual, even at a low level, the additional inducement for more serious conflict provided by proximity and major power status becomes less pronounced.

These patterns strongly support our conceptualization of opportunity and willingness as they relate to the flow of information in an ongoing and potentially hostile interaction. If conflict usually unfolds in stages, then the opportunities to engage in hostile behavior should be apparent relatively early in the conflict process (though not necessarily absent later). Save for near-equal power, the inducements we identify are straightforward measures of opportunity. Even a near-equal power ratio, which is accompanied by none of the certainties of power imbalance, opens up opportunities to probe for the possibility of gaining relative to an opponent, other things being equal. Power transition theory says that parity is an inducement to war, but our results suggest that parity is first and foremost an inducement to emerging conflicts of interest. Militarized conflict may follow, but by then the effects of near-equal power have already come to light.

The presence of conflict suppressors, on the other hand, does not imply a perfect harmony of interests according to most contemporary liberal theories about war and peace. Instead, these arguments point to an unwillingness among democratic and interdependent states to engage each other in more serious forms of conflict, in part due to domestic political and economic costs involved. Conflict happens, as these are often highly interactive dyads. Suppressors help to restrain conflict at all levels, but their impact on states' unwillingness to escalate to higher levels of hostility is more apparent later in the process after more information has been exchanged in what is essentially an ongoing bargaining interaction.

Instead of considering each influence individually as additive, it might be instructive to consider an alternative specification. Different factors are often substitutable in the sense that one (or a few) may be sufficient to provide the opportunity for interaction, and similarly for the class of factors we associate with willingness. But it is the conjunction of opportunity and willingness that constitutes causal necessity. This conceptualization implies there are multiple paths to an outcome represented by different combinations of opportunity and willingness variables (Braumoeller 2001a; Cioffi-Revilla and Starr 1995). Each type of influence constitutes an additive vector of important factors, but in contrast to the model we estimate above, a militarized dispute results from the interaction of these two vectors such that

$$
\operatorname{Pr}(y \mid \beta, X)=\Phi\left(X_{1 k} \beta_{1}\right) \times \Phi\left(X_{2 l} \beta_{2}\right),
$$


where $\Phi$ denotes the standard normal cumulative distribution function. That is, MIDs arise from two jointly necessary conditions: some combination of factors leading to opportunity conjoined with some combination of factors driving willingness. A similar conceptualization might be applied to conflict more generally, including lower level diplomatic and economic disputes. The idea of substitutability and multiple paths to war implies that the individual elements of opportunity and willingness are switched on and off in various ways for different dyads, and these different combinations place states at varying degrees of risk for violent confrontation. This empirical model, however, simply states that the extent to which each inducement is present contributes to the opportunity for conflict, that the extent to which each of the suppressors is absent contributes to willingness, and that it is the interaction of these two vectors that affects the probability of actual conflict.

We do not necessarily prefer such a specification over a purely additive one, but it is worthwhile considering it as a robustness check on the results above. ${ }^{18}$ Following Braumoeller (2001b), we estimated an "aggregated probit" model for MIDs as well as dyadic conflict generally. All of the estimates are statistically significant. Each has the same sign as before, and the rank order of importance among the variables in each vector, as indicated by percentage changes in risk, is nearly identical to those in Table 2 . The pattern evident there-the opportunity variables are more important at lower levels of the conflict process than when the dispute becomes militarized, while the reverse holds for the willingness variables - is almost perfectly replicated.

\section{Conclusion}

This article indicates the importance of further research on escalation and bargaining along the entire spectrum of conflict behavior, from mere diplomatic disputes to full-scale war. Overall, our findings correspond with Kant's understanding that all states are subject to the realist conditions of interstate competition that makes disputes likely but that the liberal influences, where present, can constrain the escalation of such disputes to war (Doyle 1997, chap. 8). Our analysis has also yielded some new and noteworthy results. First, joint IGO memberships and alliances may reflect and even promote interactions and conflicts of interest that could give rise to diplomatic disputes, but IGOs do not contribute to the escalation of lower level conflicts to militarized disputes, and alliances significantly reduce the escalation of disputes between their members. Second, while power parity and major power status also may promote the emergence of diplomatic disputes, they do not increase the probability that diplomatic conflicts will escalate to MIDs, once we account for selection effects. Third, the proposition that democracy and interdependence encourage diplomatic conflicts as signals of resolve is not supported. Joint democracy and

\footnotetext{
${ }^{18}$ These results are available from the first author on request.
} 
interdependence strongly reduce the risk that lower level conflicts will escalate to MIDs, and they also help prevent lower level conflict from emerging in the first place.

We have sought to incorporate some insights from the strategic choice literature into our statistical analysis, especially concerning the role of information and the communication of resolve. The potential for biased inferences in empirical work suggests the appropriateness of techniques that explicitly model the selection process. We employ one such method here and although our results reveal the existence of selection effects, these are fairly modest. Perhaps more important, taking seriously the possibility of selection effects in the context of a two-stage conceptualization of the conflict process leads us to think further about the role of information within the opportunity/willingness framework. We argue that the geopolitical factors affecting the opportunity for conflict, which are also the factors highlighted in realist theories, should be more important in earlier stages of the conflict process, when less information is available regarding acceptable settlements and the resolve of actors to achieve them, than in later stages. By contrast, the importance of factors affecting willingness - democratic norms and institutions and economic interdependence, as emphasized by liberal theories - should increase as the conflict process unfolds because they facilitate the flow of information relevant to the ongoing dispute. Our empirical analysis supports this argument. The microfoundations of this proposition seem to us worthy of further exploration within a choicetheoretic framework.

This investigation provides confirmation for our suspicion that the effects of various influences on the conflict process are nonmonotonic over the range of hostile behavior that states engage in, from diplomatic disputes to all-out war. The method we use, a maximum likelihood probit procedure incorporating the selection process, better fits our conceptualization than do traditional procedures. However, more methodological work remains to develop statistical techniques that more closely correspond to the strategic choice framework, which has given rise to many of the insights and propositions that empirical researchers have been examining.

A major advance in this regard is Signorino's (1999) modification of probit and logit analysis. He connects statistical estimation to the decision nodes and possible outcomes of a sequential interaction between states (e.g., a military crisis) in a way we find compelling. However, his method requires that an observed event be identifiable as one among the possible outcomes of a strategic interaction. The unit of analysis must be the sequential interaction, and one with a reasonably consistent strategic structure comprising certain moves and countermoves. MIDs, as documented and coded by the Correlates of War Project, seem to fit the bill reasonably well, but the dyad-year version of the MIDs data, which we use, does not. In the case of the events databases (COPDAB, WEIS, and PANDA), even the raw, disaggregated data are not suitable since individual events are not cross-referenced to other events that may together 
comprise a single strategic interaction. We hope further progress can be made both in events data collection and in adapting methods like Signorino's to the pooled time-series context.

Finally, the distinction between opportunity and willingness can be productively applied to theories and their policy implications for contemporary international relations. In relations between regional rivals or major powers-as in the Middle East, or between China and the United States - there will be opportunities for conflicts of interest to erupt into diplomatic or other nonmilitarized disputes, a potential likely to be aggravated by relative equality of power. It is all the more important, then, that factors suppressing the willingness to escalate conflict be strong and numerous, and for theorists and policy makers to promote those that may be available and effective. Of those underscored by liberal theory, dyadic economic ties and general openness to the global economy may not have such strong effects as joint democracy, but they are much more subject to policy initiative and choice.

\section{Manuscript submitted 27 June 2001}

Final manuscript received 18 February 2002

\section{References}

Alt, James E., Gary King, and Curtis S. Signorino. 2001. "Aggregation among Binary, Count, and Duration Models: Estimating the Same Quantities from Different Levels of Data." Political Analysis 9(1): 21-45.

Anselin, Luc. 1988. Spatial Econometrics: Methods and Models. Dordrecht: Kluwer.

Azar, Edward E. 1993. "Conflict and Peace Data Bank (COPDAB), 1948-1978," 3rd release. Center for International Development and Conflict Management, University of Maryland. Typescript.

Beck, Nathaniel, Jonathan N. Katz, and Richard Tucker. 1998. "Beyond Ordinary Logit: Taking Time Seriously in Binary-Times-Series Cross-Section Models." American Journal of Political Science 42(4): 1260-88.

Bennett, D. Scott, and Allan C. Stam. 2000. "Research Design and Estimator Choices for Analyzing Interstate Dyads: When Decisions Matter." Journal of Conflict Resolution 44(5): 653-85.

Blanton, Shannon Lindsey. 2000. "Promoting Human Rights and Democracy in the Developing World: U.S. Rhetoric versus U.S. Arms Exports.” American Journal of Political Science 44(1): 123-31.

Boehmer, Charles, Erik Gartzke, and Tim Nordstrom. 2001. "Do Intergovernmental Organizations Promote Peace?" Pennsylvania State University. Typescript.

Bond, Joe, and Doug Bond. 1998. "The Protocol for the Assessment of Nonviolent Direct Action (PANDA): Codebook for the P24 Data Set." 〈http://www.wcfia.harvard.edu/ponsacs/ DOCS/cbcontent.htm>.

Braumoeller, Bear F. 2001a. "Causal Complexity and the Study of Politics." Harvard University. Typescript.

Braumoeller, Bear F. 2001b. "Implementing nabit and nagit in Stata." Harvard University. Typescript.

Bremer, Stuart A. 1992a. "Dangerous Dyads: Conditions Affecting the Likelihood of Interstate War, 1816-1965." Journal of Conflict Resolution 36(2): 309-41.

Bremer, Stuart A. 1992b. "Democracy and Militarized Interstate Conflict, 1816-1965." International Interactions 18(3): 231-49.

Bremer, Stuart A. 1993. "Advancing the Scientific Study of War." International Interactions 19(2-3): $1-26$. 
Bueno de Mesquita, Bruce. 1981. The War Trap. New Haven, CT: Yale University Press.

Bueno de Mesquita, Bruce, and David Lalman. 1992. War and Reason: Domestic and International Imperatives. New Haven, CT: Yale University Press.

Bueno de Mesquita, Bruce, James D. Morrow, and Ethan R. Zorick. 1997. "Capabilities, Perception, and Escalation.” American Political Science Review 91(1): 15-27.

Cioffi-Revilla, Claudio, and Harvey Starr. 1995. "Opportunity, Willingness and Political Uncertainty: Theoretical Foundations of Politics." Journal of Theoretical Politics 7(4): 447-76.

Doyle, Michael W. 1997. Ways of War and Peace: Realism, Liberalism, and Socialism. New York: W.W. Norton.

Dubin, Jeffrey A., and Douglas Rivers. 1990. "Selection Bias in Linear Regression, Logit and Probit Models." Sociological Methods and Research 18(2/3): 360-90.

Eyerman, Joe, and Robert A. Hart, Jr. 1996. "An Empirical Test of the Audience Cost Proposition: Democracy Speaks Louder than Words." Journal of Conflict Resolution 40(4): 597-616.

Fearon, James. 1994a. "Domestic Political Audiences and the Escalation of International Disputes." American Political Science Review 88(3): 577-92.

Fearon, James. 1994b. "Signaling versus the Balance of Power and Interests: An Empirical Test of a Crisis Bargaining Model." Journal of Conflict Resolution 38(2): 236-69.

Fearon, James. 1995. "Rationalist Explanations for War." International Organization 49(3): 379-414.

Gartzke, Erik, and Dong-Joon Jo. 2001. "Tipping the Scale: Democracy, Interdependence, and International Conflict." Columbia University. Typescript.

Gartzke, Erik, Quan Li, and Charles Boehmer. 2001. "Investing in the Peace: Economic Interdependence and International Conflict." International Organization 55(2): 391-438.

Goertz, Gary. 1994. Contexts of International Relations. Ann Arbor: University of Michigan Press.

Goldstein, Joshua S. 1992. "A Conflict-Cooperation Scale for WEIS Events Data." Journal of Conflict Resolution 36(2): 369-85.

Heckman, James J. 1979. "Sample Selection Bias as a Specification Error." Econometrica 47(1): 153-61.

Huth, Paul K. 1996. Standing Your Ground: Territorial Disputes and International Conflict. Ann Arbor: University of Michigan Press.

Huth, Paul K. 2002. The Democratic Peace and Territorial Conflict in the Twentieth Century. Cambridge: Cambridge University Press.

King, Gary. 1989. Unifying Political Methodology: The Likelihood Theory of Statistical Inference. Cambridge: Cambridge University Press.

Kugler, Jacek, and Douglas Lemke. 1996. Parity and War: Evaluations and Extensions of The War Ledger. Ann Arbor: University of Michigan Press.

Layne, Christopher. 1995. "Kant or Cant: The Myth of the Democratic Peace." International Security 19(3): 5-49.

Leeds, Brett Ashley, and David R. Davis. 1999. "Beneath the Surface: Regime Type and International Interaction, 1953-78." Journal of Peace Research 36(1): 5-21.

Lemke, Douglas. 1995. "The Tyranny of Distance: Redefining Relevant Dyads." International Interactions 21(1): 23-38.

Lemke, Douglas, and William Reed. 2001a. "The Relevance of Politically Relevant Dyads." Journal of Conflict Resolution 43(1): 126-44.

Lemke, Douglas, and William Reed. 2001b. "War and Rivalry among the Great Powers." American Journal of Political Science 45(2): 457-69.

Maoz, Zeev. 1996. Domestic Sources of Global Change. Ann Arbor: University of Michigan Press.

Maoz, Zeev. 1998. "Realist and Cultural Critiques of the Democratic Peace: A Theoretical and Empirical Re-assessment." International Interactions 24(1): 1-89.

Maoz, Zeev, and Bruce Russett. 1993. "Normative and Structural Causes of the Democratic Peace, 1946-1986." American Political Science Review 87(3): 624-38.

Meernik, James. 2000. "Modeling International Crises and the Political Use of Military Force by the USA." Journal of Peace Research 37(5): 547-62. 
Mintz, Alex, and Nehemia Geva. 1993. "Why Don't Democracies Fight Each Other? An Experimental Study." Journal of Conflict Resolution 37(3): 484-503.

Morrow, James D. 1989. "Capabilities, Uncertainty, and Resolve: A Limited Information Model of Crisis Bargaining." American Journal of Political Science 33(4): 941-72.

Morrow, James D. 2000. "On Microfoundations and Methodology in the Study of International Conflict: Assessing the Democratic Peace and Offense-Defense Theory." Presented at the American Political Science Association conference on the State of the Discipline, Washington, DC.

Most, Benjamin, and Harvey Starr. 1989. Inquiry, Logic, and International Politics. Columbia: University of South Carolina Press.

O’Loughlin, John V. 1986. "Spatial Models of International Conflicts: Extending Current Theories of War Behavior." Annals of the Association of American Geographers 76: 63-80.

Oneal, John R., and Bruce Russett. 1999a. "Assessing the Liberal Peace with Alternative Specifications: Trade Still Reduces Conflict." Journal of Peace Research 36(4): 423-32.

Oneal, John R., and Bruce Russett. 1999b. "The Kantian Peace: The Pacific Benefits of Democracy, Interdependence, and International Organizations, 1885-1992." World Politics 52(1): 1-37.

Reed, William. 2000. "A Unified Statistical Model of Conflict Onset and Escalation." American Journal of Political Science 44(1): 84-93.

Rock, Stephen R. 1997. "Anglo-U.S. Relations, 1845-1930: Did Shared Liberal Values and Democratic Institutions Keep the Peace?" In Paths to Peace: Is Democracy the Answer?, ed. Miriam Fendius Elman. Cambridge, MA: MIT Press.

Rummel, R. J. 1995. "Democracies ARE Less Warlike than Other Regimes." European Journal of International Relations 1(4): 457-79.

Russett, Bruce. 1995. "The Democratic Peace: And Yet It Moves.” International Security 19(4): $164-75$.

Russett, Bruce. 2003. "Violence and Disease: Trade as Suppressor to Conflict when Suppressors Matter." In Economic Interdependence and International Conflict: New Perspectives on an Enduring Debate, eds. Edward Mansfield and Brian Pollins. Ann Arbor: University of Michigan Press.

Russett, Bruce, and John R. Oneal. 2001. Triangulating Peace: Democracy, Interdependence, and International Organizations. New York: W.W. Norton.

Schrodt, Philip A., and Deborah J. Gerner. 2000. Analyzing International Event Data: A Handbook of Computer-Based Techniques. University of Kansas. On-line manuscript, 〈http://www.ukans.edu/ $\sim$ keds/papers.html $\rangle$.

Schroeder, Paul W. 2000. "International Politics, Peace, and War, 1815-1914." In The Short Oxford History of Europe: The Nineteenth Century, ed. T. C. W. Blanning. Oxford: Oxford University Press.

Schultz, Kenneth A. 1998. "Domestic Opposition and Signaling in International Crises." American Political Science Review 94(4): 829-44.

Schultz, Kenneth A. 1999. "Do Domestic Institutions Constrain or Inform? Contrasting Two Institutional Perspectives on Democracy and War." International Organization 53(2): 233-66.

Schultz, Kenneth A. 2002. Democracy and Coercive Diplomacy. Cambridge: Cambridge University Press.

Signorino, Curtis S. 1999. "Strategic Interaction and the Statistical Analysis of International Conflict." American Political Science Review 93(2): 279-98.

Siverson, Randolph, and Harvey Starr. 1991. The Diffusion of War: A Study of Opportunity and Willingness. Ann Arbor: University of Michigan Press.

Smith, Alastair. 1998a. "International Crises and Domestic Politics." American Political Science Review 92(3): 623-38.

Smith, Alastair. 1998b. "A Summary of Political Selection: The Effect of Strategic Choice on the Escalation of International Crises." American Journal of Political Science 42(2): 698-701.

Starr, Harvey. 1992. "Democracy and War: Choice, Learning, and Security Communities." Journal of Peace Research 29(2): 207-13. 
Thagard, Paul. 1999. How Scientists Explain Disease. Princeton, NJ: Princeton University Press.

Tomlinson, Rodney G. 1993. "World Event/Interaction Survey (WEIS): Coding Manual." 6th ed. United States Naval Academy. Typescript.

Wagner, R. Harrison. 2000. "Bargaining and War." American Journal of Political Science 44(3): 469-84.

Waltz, Kenneth. 1979. Theory of International Politics. Reading, MA: Addison-Wesley.

David Kinsella is associate professor of political science, Portland State University, Portland, OR 97207-0751.

Bruce M. Russett is Dean Acheson Professor of international relations, Yale University, New Haven, CT 06520-8301. 